\title{
mTOR and MAPK: from localized translation control to epilepsy
}

\author{
Helena F. Pernice, Rico Schieweck, Michael A. Kiebler and Bastian Popper ${ }^{*}$ []
}

\begin{abstract}
Background: Epilepsy is one of the most common neurological diseases characterized by excessive hyperexcitability of neurons. Molecular mechanisms of epilepsy are diverse and not really understood. All in common is the misregulation of proteins that determine excitability such as potassium and sodium channels as well as GABA receptors; which are all known as biomarkers for epilepsy. Two recently identified key pathways involve the kinases mechanistic target of rapamycin (mTOR) and mitogen-activated protein kinases (MAPK). Interestingly, mRNAs coding for those biomarkers are found to be localized at or near synapses indicating a local misregulation of synthesis and activity.

Results: Research in the last decade indicates that RNA-binding proteins (RBPs) responsible for mRNA localization, stability and translation mediate local expression control. Among others, they are affected by mTOR and MAPK to guide expression of epileptic factors. These results suggest that mTOR/MAPK act on RBPs to regulate the fate of mRNAs, indicating a misregulation of protein expression at synapses in epilepsy.

Conclusion: We propose that mTOR and MAPK regulate RBPs, thereby guiding the local expression of their targetmRNAs encoding for markers of epilepsy. Thus, misregulated mTOR/MAPK-RBP interplay may result in excessive local synthesis of ion channels and receptors thereby leading to hyperexcitability. Continuous stimulation of synapses further activates mTOR/MAPK pathway reinforcing their effect on RBP-mediated expression control establishing the basis for epilepsy. Here, we highlight findings showing the tight interplay between mTOR as well as MAPK with RBPs to control expression for epileptic biomarkers.
\end{abstract}

Keywords: RBP, mTOR, MAPK, ERK, Epilepsy

\section{Background}

Epilepsy is one of the most common neurological diseases, affecting about 65 million people in the world [1], therein 8.5 per 1000 population in the US [2] and 18 per 1000 population in Europe [3]. The disease affects life quality through discrimination and segregation of patients [4]. Furthermore, therapies have high economic costs of up to $\$ 13.8$ billion in Europe [5]. Available therapies usually target symptoms and are still ineffective in $30 \%$ of all cases [6]. It is commonly believed that abnormal synchronous firing in a hyperexcitable neuronal network results in epileptic seizures [7]. Generally, epilepsy can be differentiated according to the region of its

*Correspondence: Bastian.Popper@med.uni-muenchen.de Department of Anatomy and Cell Biology, Biomedical Center (BMC), Medical Faculty, Ludwig-Maximilians-University (LMU), Großhaderner Straße 9, 82152 Planegg-Martinsried, Germany generation: Generalized seizures origin from both hemispheres, whereas focal epilepsy derives from one specific area of the brain, most commonly the temporal lobe or the limbic system, which results in temporal lobe epilepsy (TLE) [8]. Idiopathic epilepsies that can take both generalized and focal forms, have a genetic or epigenetic cause, classifying genetic epilepsy as one specific group [9]. In the last decade, immense effort was made to identify mutations ending up with a list of genetic risk factors causing epilepsy [10,11] (Table 1). In $40 \%$ of the cases, however, the etiology of epilepsy is unknown. This emphasizes the need for a better understanding of genetic causes forming the basis of putative therapies.

The genetic risk factors that have been found are diverse and are involved in regulation of various pathways affecting cell death, morphology and neurogenesis. One aspect that is essential for all models of epileptogenesis is 
Table 1 Epilepsy targets that are regulated by RBPs and dependent on mTOR/MAPK activity

\begin{tabular}{|c|c|c|c|c|c|}
\hline & \multirow[t]{2}{*}{ Effect } & \multirow[t]{2}{*}{ Pathway } & \multicolumn{2}{|c|}{ Epilepsy related targets } & \multirow[t]{2}{*}{ Link to epilepsy } \\
\hline & & & Gene & Protein & \\
\hline \multirow[t]{6}{*}{ FMRP } & \multirow{6}{*}{$\begin{array}{l}\text { Translational repression and dendritic RNA } \\
\text { transport [48] }\end{array}$} & mTOR [57-61] & CaMKIla & CaMKIla $[20,48]$ & \multirow{3}{*}{$\begin{array}{l}\text { Childhood seizures in patients and mice with } \\
\text { FXS }[27,56]\end{array}$} \\
\hline & & \multirow[t]{5}{*}{$\operatorname{MAPK}[20,62,65]$} & KCNC1 & Kv3.1 [52] & \\
\hline & & & KCND2 & Kv4.2 [54] & \\
\hline & & & CACNA1B & Cav2.2 [53] & Audiogenic seizures in rats with FXS [62] \\
\hline & & & KCNMA1 & BK channel [51] & \\
\hline & & & KCNT1 & Slack channel [50] & \\
\hline \multirow[t]{3}{*}{ HuD } & RNA stabilization & $\operatorname{mTOR}[76,77,79]$ & CaMKIla & CaMKIlla [77] & \multirow{2}{*}{$\begin{array}{l}\text { Increased protein level in rats with kainate } \\
\text { induced seizures [70] }\end{array}$} \\
\hline & Splicing control & \multirow[t]{2}{*}{ MAPK $[76,80]$} & KCNA1 & Kv1.1 [69] & \\
\hline & Neuronal differentiation and plasticity [67] & & GLS & Glutaminase [73] & $\begin{array}{l}\text { Increased susceptibility to audiogenic } \\
\text { seizures in mice [28] }\end{array}$ \\
\hline \multirow[t]{3}{*}{ HuR } & RNA stabilization & \multirow[t]{3}{*}{ MAPK [82-85] } & \multirow[t]{3}{*}{ GAP-43 } & \multirow[t]{3}{*}{ GAP-43 $[68,72]$} & \multirow{3}{*}{$\begin{array}{l}\text { Pentylenetetrazol-induced seizures in mice } \\
\text { [82] }\end{array}$} \\
\hline & Splicing control [86] & & & & \\
\hline & Cellular stress response [67] & & & & \\
\hline CREB & Translational activator [89] & MAPK [40] & Bdnf & BDNF $[29,92]$ & $\begin{array}{l}\text { Epileptic seizures in animal models of } \\
\text { epilepsy and human patients [29] }\end{array}$ \\
\hline
\end{tabular}

RBPs, their general effect on gene expression, involvement in mTOR and/or MAPK pathways, their mRNA targets, and encoded proteins as well as their link to epilepsy in animal models and human patients are depicted

the dysregulation of synaptic function. This includes presynaptic vesicle release, postsynaptic receptor expression and ion channel expression, which have provided new approaches on therapy for epilepsy [12, 13].

Recently, it has been shown that the mechanistic target of rapamycin (mTOR) and mitogen-activated protein kinases (MAPK) are important regulators of synaptic excitability involved in cognitive impairment and epilepsy in animal models as well as human disease [14-16]. Those kinases regulate gene expression in neurons in a stimulus-dependent manner [17, 18]. Both pathways can be activated i.e. by long-term potentiation (LTP), a process characterized by enhanced transmission between simultaneously activated synapses. Still, not all neuronal stimulation paradigms lead to the activation of both mTOR and MAPK pathways [19, 20]. Further research is necessary to describe the exact mechanisms and kind of neuronal excitation that leads to hyperactivity. Regardless, multiple key studies show an effect of mTOR and MAPK on general expression control [21, 22]. Remarkably, recent research has shown that both mTOR and MAPK also act locally to regulate protein expression at activated synapses [17, 22]. Together, these findings provide new insight into the molecular mechanisms of epilepsy and explain how lack of pathway control results in seizures.

\section{RNA-binding proteins: mediators of remote expression control}

Research in the last decade has shown that RNA-binding proteins (RBPs) are essential regulators of protein expression. For local gene expression, it was shown that RBPs regulate gene expression in a spatially restricted manner. mRNAs sequester RBPs by binding motifs in their $3^{\prime}$-untranslated region (3'-UTR). 3'-UTRs of localized transcripts are generally longer and more complex harboring cis-acting sequence motifs and secondary structures as binding platforms. It is commonly believed that some RBPs form large RNA-protein complexes termed RNA granules. These granules are transported along the cytoskeleton to synapses [23]. Upon stimulation, those particles are unpacked, the mRNA is released and locally translated. The process of remote expression control is mediated by RBPs. They control different steps of posttranscriptional regulation such as mRNA transport, translation and mRNA stability (reviewed in [24, 25]). The synchronization of all three steps is a prerequisite for local protein expression. Therefore, translation regulators such as Pumilio2 (Pum2) are part of transport granules as it was shown for Staufen2 (Stau2) [26]. The relevance of RBPs for the occurrence of neurological and neuropsychiatric diseases has risen in the last years. Both loss of function and gain of function mutations of RBPs result in epileptic phenotypes [27-29]. There is evidence that known epilepsy targets are under control of RBPs suggesting a local expression control of those mRNAs; probably at synapses. RBPs regulate mRNA distribution and protein synthesis of known epilepsy targets such as CaMKIIa or KCNA1 encoding for the potassium channel Kv1.1, as well as multiple other ion channels [30]. It is therefore tempting to postulate that any aberrant translational control of newly synthesized proteins for regulators of synaptic excitability, e.g. ion channels or receptors, leads to epilepsy. 


\section{Dysregulation of mTOR-mediated expression control leads to epileptic seizures}

mTOR is a serine-threonine kinase that forms two protein complexes termed mTORC1 and mTORC2 [31]. mTORC1 consists of five components: mTOR as active center, raptor, MLST8, PRAS40 and DEPTOR. It is generally believed that mTOR acts mainly on translation. As a central check point, mTORC1 senses both internal and external signals such as nutrient and growth factor availability as well as oxidative stress to guide protein synthesis. mTORC2 is a rapamycin insensitive complex that contributes to cell survival functions, metabolism, proliferation and actin polymerization [31]. The exact role of mTORC2 in cellular signaling is still unclear. Several neuropathological diseases such as autism, depression and epilepsy have been linked to dysregulation of both complexes [17].

mTOR is a major player in the generation of neuronal homeostasis. Important factors for its maintenance is the balance of GABAergic and glutamatergic signaling, both of which are regulated by mTOR signaling [32]. Elevated activity of mTORC1 is implicated with increased neuronal excitability [31]. The relevance of mTOR regarding temporal lobe epilepsy in animal models and patients has been rising in importance throughout the last decade [33-35]. Various genetic diseases displaying a grave epileptic phenotype, like tuberous sclerosis, phosphatase and tensine homolog (PTEN)-hamartoma tumor syndromes and fragile $\mathrm{X}$ mental retardation syndrome (FXS), are associated with dysregulation of mTOR expression and activity [17]. Specifically, excessive mTOR signaling through a mutation in the tuberous sclerosis complex (TSC1/2) leads to hippocampal hyperexcitability linking mTOR with temporal lobe epilepsy [36]. Seizures generated in the hippocampus have also been related to hyperactive mTOR signaling in a mouse model harboring PTEN mutations. Knock-out of PTEN leads to hyperactive mTOR causing seizures generated in the hippocampus, mimicking the epileptic phenotype of focal cortical dysplasia [37]. Thus, controllability of excitability by mTOR is crucial to maintain balanced firing of neurons.

\section{Expression control by the MAPK pathway: a regulator of epileptic biomarkers}

The mitogen-activated protein kinase (MAPK) family consists of three pathways, the extracellular signal regulated kinase (ERK) pathway, the p38 pathway and C-Jun $\mathrm{N}$-terminal kinases (JNK) pathway. All three are highly conserved serine-threonine kinases that respond to nutrition and growth factors availability as well as neuronal activation [38]. ERK stimulates the expression of $N$-methyl-D-aspartate (NMDA) receptors causing synaptic excitability. This, in turn, leads to seizures [38]. Moreover, the neuroprotective effect of NMDA injected in mice before seizure induction is diminished by inhibition of the MAPK pathway, further underlining the potential of MAPK to regulate neuronal excitability [39]. Also the induction of mossy fiber sprouting, an effect causally associated with epileptogenesis, by the ERK/MAPK pathway has been shown in rats after traumatic brain injury [40]. This further supports a role of MAPK pathway in epileptogenesis. Interestingly, MAPK responds to different seizures-inducing treatments: maximal electroshock seizures in mice [41], kainate [42], pilocarpine [43] and pentylenetetrazole [44] as well as dopamine D1 receptor $\left(D_{1} R\right)$ agonist [45]. These findings suggest a role of MAPK in epileptogenesis.

Strikingly, there is evidence that also the MAPK pathway involves RBPs that are misregulated in epilepsy, like FMRP and HuR. In this context, kinases regulate those proteins and, therewith, their ability to control posttranscriptional gene expression [22, 46].

\section{mTOR and MAPK pathways control RBPs and thereby protein expression}

Some of the RBPs mentioned above are guided by mTOR/MAPK. Thus, it has been suggested that mTOR/ MAPK affect local gene expression by regulating RBPs. In this review, we will focus on the effect of mTOR and MAPK on RBPs linking local expression control with neuronal hyperexcitability in epilepsy. We focus on localized transcripts at or near synapses that encode for proteins causing epilepsy. In addition, we emphasize that RBPs (1) regulate expression of those epilepsy targets and (2) are involved in the mTOR and/or MAPK pathway (Fig. 1). Together, mTOR/MAPK mediated control of RBPs represent a novel mechanism of remote expression control. In the following paragraphs, we will focus on RBPs already shown to be regulated by the mTOR and/or MAPK pathway.

\section{FMRP}

Mutations in the fragile X mental retardation gene ( $f m r 1)$ coding for the translation regulator FMRP lead to activity-dependent misregulation of protein synthesis at synapses and can result in seizures [27]. FMRP is an RBP involved in dendritic transport and translation control 


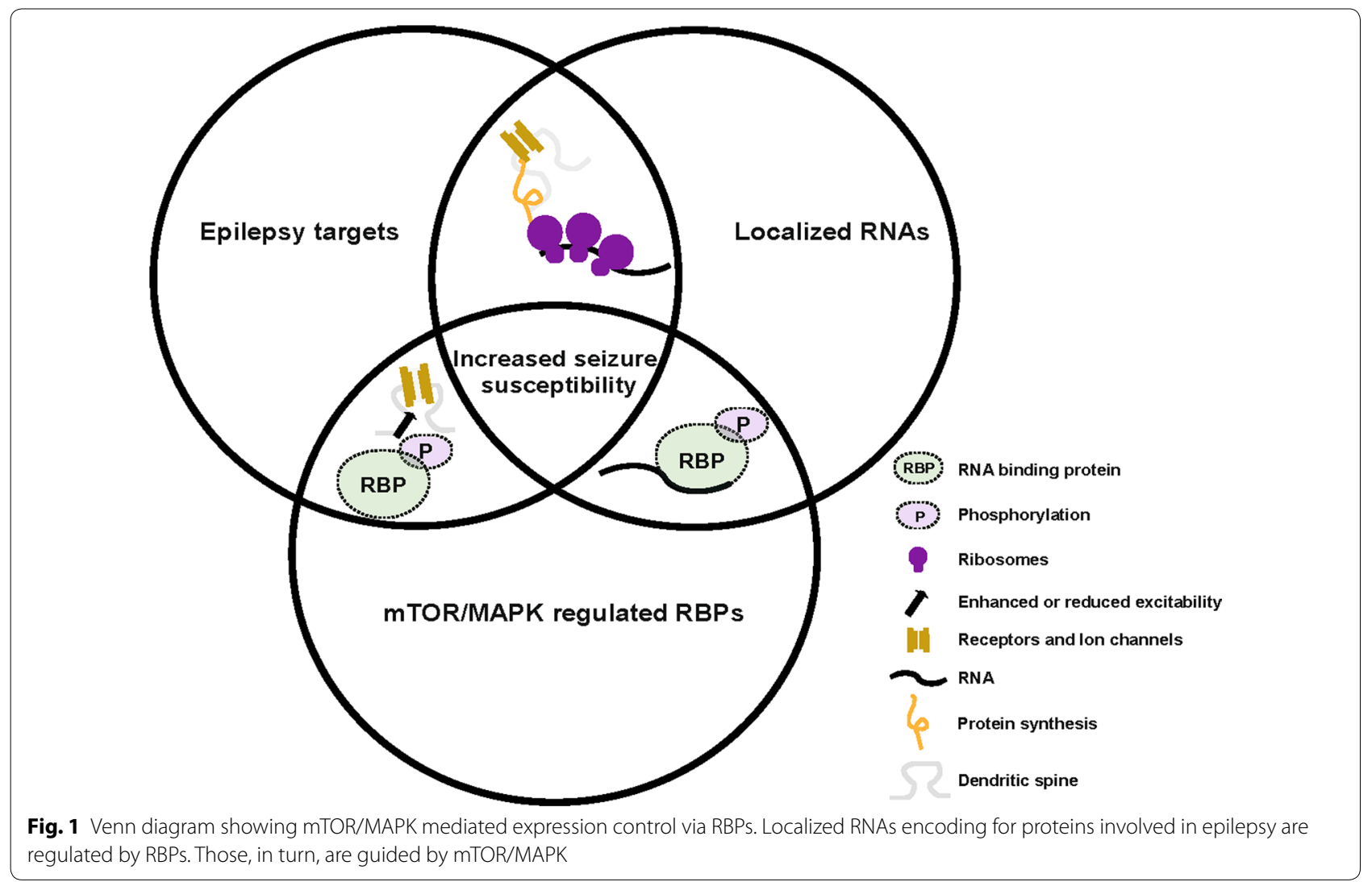

[47], specifically as a translational repressor [48]. It regulates the synthesis of calcium/calmodulin dependent protein kinase II alpha (CaMKII $\alpha$ ) that influences synaptic plasticity [49], the expression of multiple ion channels [50-54] and can lead causes epilepsy in knock-out mutant mice [55].

FMRP loss of function causes fragile X syndrome (FXS). Interestingly, FXS patients also suffer from seizures [56]. Furthermore, there is supportive evidence for a role of FMRP in temporal lobe epilepsy: In patients with temporal lobe epilepsy and in rats treated with the seizureinducing drug pilocarpine, the level of cytosolic FMRP binding protein (CYFIP1) is elevated [57]. CYFIP is a protein expressed at synapses, displaying multiple functions like local regulation of actin cytoskeleton dynamics and dendritic spine morphology [57]. Interestingly, morphological abnormalities resulting from overexpressed CYFP1 can be rescued by the mTOR inhibitor rapamycin [58] linking mTOR activity with a direct FMRP interactor. Furthermore, it has been shown that elevated levels of phosphorylated mTOR is associated with decreased FMRP [59]. Additionally, regulation of FMRP via the mTOR target p70-S6 kinase (S6K1) has been proposed [60]. S6K1 phosphorylates FMRP and, thereby, it regulates its ability to repress translation. Surprisingly, the phosphorylation of FMRP has been reported to be mTOR independent [61] indicating an indirect effect of mTOR on FMRP-mediated expression control. Together, these results suggest that FMRP and mTOR are influencing each other to fine-tune protein expression.

The MAPK pathway is generally activated upon neuron stimulation. Activation of glutamate receptors, i.e. NMDA receptors, plays an important role in the generation of hyperactive firing of neurons. In this respect, activation of the metabotropic glutamate receptor 5 (mGluR5) results in excessive protein production in $\mathrm{fmr} 1$ knockdown mice [20]. Interestingly, young FXS rats are susceptible to audiogenic seizures [62]. One hypothesis 
states that elevated protein levels at synapses leads to seizures [27, 63]. In contrast, mGluR5 does not directly influence chemically induced epilepsy in rats [64]. Inhibition of mGluR 5 corrects symptoms of fragile X syndrome in adult mice and, importantly, reduces overactive ERK and mTOR signaling [65]. Furthermore, a direct link has been suggested from mGluR5 activation to mTOR and MAPK pathways in modulating FMRP-mediated expression control [66]. Importantly, the fragile $\mathrm{X}$ syndrome phenotype can be reversed by blocking ERK activity suggesting an interplay between FMRP and the ERK pathway $[20,62]$. Since FXS-patient also suffer from seizures, those results indicate also a possible link to epilepsy.

\section{Hu protein family}

Another group of RBPs connected to neurological disease is the $\mathrm{Hu}$ protein family (reviewed in [67]). Hu proteins are related to the embryonic lethal abnormal vision protein family (Elav) and were first described in patients with paraneoplastic encephalomyelitis [68]. These proteins are primarily responsible for neuronal differentiation, learning and memory, as well as long-term potentiation. They exert their RNA stabilizing function via three highly conserved RNA recognition motifs binding to AU-rich regions in the $3^{\prime}$-UTR, in the polyA tail [68] and in the coding region [69].

One member of the $\mathrm{Hu}$ family is $\mathrm{HuD}$ that regulates gene expression in neurons. $\mathrm{HuD}$ is upregulated after kainate-induced seizures in rats and shows activity dependent increase in protein levels in hippocampal neurons [70, 71]. Additionally, HuD localizes in an activity dependent manner in dendrites and interacts with mTOR targets in $\mathrm{KCl}$ stimulated hippocampal neurons [72]. DeBoer et al. showed that HuD knockout mice also show increased susceptibility to auditory seizures [28]. Supportive for these findings are results from other groups indicating a role of $\mathrm{HuD}$ in the regulation of synaptic excitability by adjusting the cellular glutamate levels via translation control of the glutaminase [73]. Unbalanced glutamate levels and related receptors are responsible for epileptogenesis [74]. Work by Sosanya et al. indicates an antagonistic relationship between $\mathrm{HuD}$ and mTOR in regulating expression of the voltage-gated potassium channel $1.1\left(\mathrm{~K}_{\mathrm{v}} 1.1\right)$ expression [69]. mTOR inhibition leads to degradation of $\mathrm{HuD}$ targets thereby increasing the concentration of free $\mathrm{HuD}$ molecules that are binding $\mathrm{K}_{\mathrm{v}} 1.1$ mRNA more efficiently. Hence, $\mathrm{K}_{\mathrm{v}} 1.1$ expression is increased upon mTOR-inhibition [21, 69]. Low Kv1.1 levels are associated with increasing seizure frequency in kainate induced temporal lobe epilepsy in rats, correlating with high mTOR levels [75].

$\mathrm{HuD}$ has been shown to control changes in synaptic plasticity via the local translation of synaptic proteins such as CaMKII [76]. Recent reports point to the interplay of the mTOR pathway with $\mathrm{HuD}$-mediated expression control guiding branch specific expression of CaMKII $\alpha$ [77]. Proper cellular and subcellular expression of CaMKII $\alpha$ is crucial for neuronal excitability. Consequently, dysfunctions might contribute to epilepsy [78].

Importantly, inhibition of the protein kinase B (Akt)/ glycogen synthase kinase 3 (GSK3) pathway leads to changes in $\mathrm{HuD}$ and $\mathrm{HuR}$ protein levels [76]. The GSK3 pathway therefore represents a link between the mTOR, Akt and MAPK pathways [79]. This suggests an interplay in the control of $\mathrm{HuD}$ between the different kinases. Together, these findings indicate that mTOR is necessary to guide $\mathrm{HuD}$-mediated expression control. CaMKII $\alpha, K_{\mathrm{v}} 1.1$ and glutaminase mRNAs are known $\mathrm{HuD}$ targets influencing neuronal excitability. Disruption of $\mathrm{HuD}$ expression control results in hyperactivity and seizures.

Additionally, neuronal activity causes $\mathrm{HuD}$ to localize in dendrites and dendritic spine like protrusions in primary hippocampal neurons [76]. Furthermore, it colocalizes with the eukaryotic translation initiation factor $4 \mathrm{E}$ (eIF4E) suggesting regulation of translation. Known as a target of mTOR mediated translation activation via $4 \mathrm{E}$-binding protein (4EBP), elF4E is a point of convergence between the mTOR and the MAPK pathway. This was observed in mGluR dependent LTP. Activation of mGluR leads to ERK2 activation, which further phosphorylates and activates MAPK interacting kinase 2 (Mnk2) leading to eIF4E phosphorylation [80]. mGluR activation also recruits the phosphoinositide 3-kinase (PI3K)/ mTOR pathway [81], releasing the $4 \mathrm{E}$ binding protein 2 (4EBP2) mediated inhibition of elF4E and promoting translation [80].

$\mathrm{HuR}$ is another well-studied member of the Hu family and ubiquitously expressed. Activation of the MAPK pathway by anisomycin causes stabilization of survival motor neuron (SMN) mRNA by HuR [82]. Furthermore, several studies reveal the MAPK pathway 
to regulate $\mathrm{HuR}$ [82-84]. In a mouse pentylenetetrazole model of epilepsy, HuR target mRNAs in the hippocampus were analyzed [85]. Amongst them were identified genes encoding for mossy fiber sprouting and apoptosis, which contribute to epilepsy [85]. In addition, GAP-43 encoding for homonymous protein involved in axon growth is bound [86] and stabilized by HuR [76]. Importantly, GAP-43 is a marker for progressive epilepsy in patients with focal cortical dysplasia [87].

\section{CREB}

cAMP response element binding protein (CREB) is a transcription activator [88]. It has been shown that it is crucial for the induction of LTP [89]. In a genomewide microarray analysis of hippocampal tissue from patients with temporal lobe epilepsy, the protein kinase A (PKA)/CREB pathway appeared as one of the most enriched [90]. In addition, activation of CREB appears to cause epilepsy in rodent and human models [29]. Furthermore, CREB-regulated transcription coactivator 1 (CRTC1) has been shown to translocate into hippocampal nuclei following pilocarpine-induced status epilepticus [91]. CREB does not only influence transcription in the nucleus, but also leads to cell wide supply of protein and mRNA that can localize to the synapse when the synapse has been tagged, thereby permitting LTP [88, 89]. One transcript targeted by CREB is the brain derived neurotrophic factor (BDNF) [92], which has been associated to temporal lobe epilepsy in many cases [93] and may serve as a serum marker for epilepsy [94].

It is interesting to note that the MAPK pathway is a known regulator of CREB [40, 95]. Furthermore, the MAPK-CREB pathway induces mossy fiber reorganization after traumatic brain injury in rats, a characteristic feature of epileptogenesis [40]. In the human neocortex of epilepsy patients, a specific ERK activation pattern was linked to CREB phosphorylation and followed by enhanced transcription of CREB targets such as $B D N F$ [96]. Additionally, increased synaptic density was observed in these layers linking synaptic morphology with CREB-induced $B D N F$ transcription. Interestingly, it has been shown that BDNF induces synthesis of the early growth response factor 3 (EGR3) which regulates GABA receptors indicating a role of CREB in neuronal excitability [96]. These results highlight the causal link of MAPK activation and its effect on RBP-mediated expression control.

\section{Conclusions}

It is generally believed that epilepsy results from hyperexcitability and synchronous firing of neurons [7]. In the last decade, many biomarkers such as potassium and sodium channels as well as GABA receptors have been identified (Table 1). Beside those, mTOR and MAPK also contribute to epileptogenesis. Very often they are key players of converging pathways. Nonetheless, the underlying molecular mechanism of hyperexcitability and, in consequence, synchronous firing remain elusive. Strikingly, it has been shown that transcripts encoding for some of epileptic biomarkers including $m T O R$ are localized in dendrites. Additionally, RBPs, mediators of RNA localization and remote expression control, have been linked to epilepsy bridging mTOR signaling with spatially restricted expression. We propose that hyperactive mTOR and MAPK affect RBPs and RBP-mediated expression control locally (Fig. 2). Thereby, they influence transcript transport, stability and translation at or near synapses of RBP target mRNAs. Thus, increased, local expression of ion channels and receptors results in enhanced synaptic density of excitability regulating proteins and, eventually, in increased synaptic transmission. In turn, augmented synaptic stimulation further activates mTOR and MAPK. This spatially restricted misregulation of synaptic excitability may therefore represent an accelerator of synchronous, neuronal firing that eventually results in seizures. Thus, RBPs might represent a novel category of epileptic biomarkers that can help to diagnose epilepsy in patients. Furthermore, they also can serve as additional targets for therapeutics. However, future studies will elucidate their eligibility for diagnosis and therapy.

In conclusion, remote expression control that is regulated by mTOR and MAPK provides new approaches to understand epilepsy at a molecular and cellular level. Here, mTOR possibly regulates RBPs, i.e. via direct phosphorylation, to guide their expression control abilities. This regulation of RBPs via mTOR may be affected by inhibiting drugs such as Rapamycin. A recent phase 3 study on Everolimus, a Rapamycin analog, shows a positive effect on therapy resistant focal epilepsy related to tuberous sclerosis [97]. This points to a significant role of mTOR inhibitors in epilepsy, and suggests a potential for the therapy of epilepsy caused by RBP deficiency. Nevertheless, more insight is necessary to develop new diagnosis and therapy strategies for the treatment of epilepsy and to understand side effects of mTOR and MAPK inhibition [98]. 


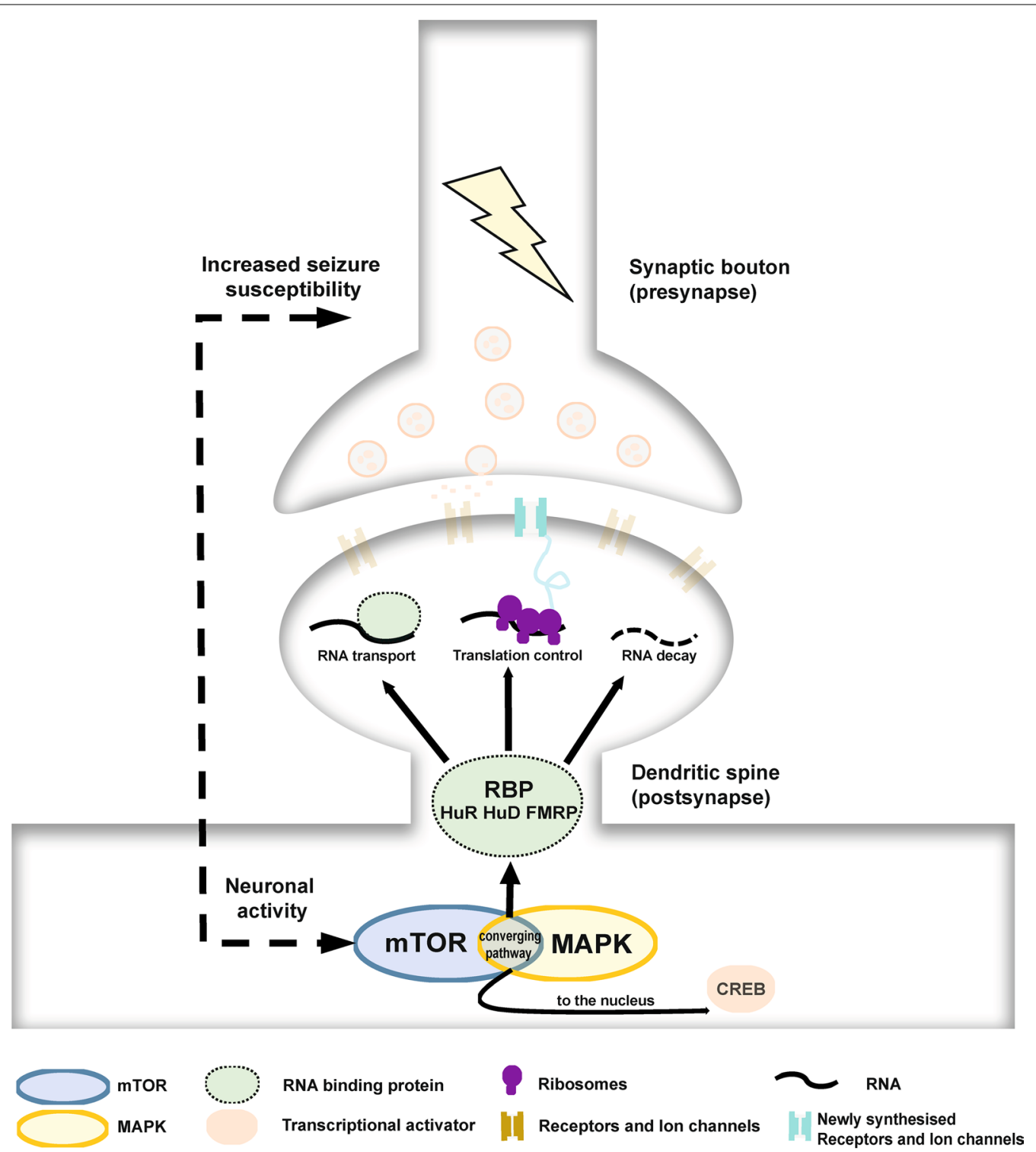

Fig. 2 Model of mTOR and MAPK mediated RBP-dependent expression control. Regulation of spatially restricted protein expression is guided by RBPs. mTOR and MAPK both regulate RBPs. The kinases influence the ability of RBPs to control RNA stability and translation thereby affecting protein levels at the synapse. Misregulation of mTOR and MAPK pathways have been linked to epilepsy. We propose that disturbed regulation of local protein expression causes overburden levels of epilepsy factors resulting in hyperexcitability and eventually seizures

\section{Abbreviations}

4EBP: 4E binding protein; Akt: protein kinase B; BDNF: brain derived neurotrophic factor; BK channel: calcium activated potassium channel; CaMKIla: calcium calmodulin dependent protein kinase II alpha; Cav2.2: voltage gated calcium channel 2.2; CREB: CAMP response element binding protein; CRTC1: CREB-regulated transcription coactivator 1; CYFIP1: cytosolic FMRP binding protein; EGR3: early growth response factor 3; elF4E: eukaryotic translation initiation factor 4E; Elav: embryonic lethal abnormal vision protein family; ERK: extracellular signal regulated kinase; Fmr1: fragile $X$ mental retardation gene; FXS: fragile X mental retardation syndrome; GABA: gamma-aminobutyric acid; GAP-43: growth associated protein 43; GSK3: glycogen synthase kinase 3; JNK: C-Jun-N-terminal kinase; Kv1.1: voltage-gated potassium channel 1.1; Kv3.1: voltage-gated potassium channel 3.1; Kv4.2: voltage-gated potassium channel 4.2; MAPK: mitogen-activated protein kinase; mTOR: mechanistic target of rapamycin; mGluR: metabotropic Glutamate receptor; NMDA: N-methyl-D-aspartate; PI3K: phosphoinositide 3-kinase; PKA: protein kinase A; PTEN: phosphatase and tensine homolog; RBP: RNA binding protein S6K: p70-S6 kinase; Slack channel: Slack sodium activated potassium channel; SMN: survival motor neuron; TLE: temporal lobe epilepsy; TSC: tuberous sclerosis complex.

\section{Authors' contributions}

HFP, RS, MAK and BP wrote the manuscript. All authors read and approved the final manuscript.

\section{Competing interests}

The authors declare that they have no competing interests. 


\section{Funding}

This work was supported by the Boehringer Ingelheim Fonds - BIF dedicated to RS, the Förderprogramm für Forschung und Lehre-FöFoLe PhD program of the LMU Munich (30/2015) dedicated to HFP, DFG (FOR 2333 TP08) dedicated to MAK and the Friedrich-Baur-Stiftung (02/14) dedicated to BP. The authors declare no competing financial interests.

Received: 29 June 2016 Accepted: 9 November 2016 Published online: 17 November 2016

\section{References}

1. Moshé SL, Perucca E, Ryvlin P, Tomson T. Epilepsy: new advances. Lancet. 2015:385:884-98

2. Helmers SL, Thurman DJ, Durgin TL, Pai AK, Faught E. Descriptive epidemiology of epilepsy in the U.S. population: a different approach. Epilepsia. 2015;26:942-8

3. Forsgren L, Beghi E, Õun A, Sillanpää M. The epidemiology of epilepsy in Europe-a systematic review. Eur J Neurol. 2005;12:245-53.

4. Prilipko L, Saxena S, Boer H. Atlas: epilepsy care in the world. Book. 2005;129:91.

5. Olesen J, Gustavsson A, Svensson M, Wittchen HU, Jönsson B. The economic cost of brain disorders in Europe. Eur J Neurol. 2012;19:155-62.

6. Eadie MJ. Shortcomings in the current treatment of epilepsy. Expert Rev Neurother. 2012;12:1419-27.

7. Scharfman HE. The neurobiology of epilepsy. Curr Neurol Neurosci Rep. 2007:7:348-54.

8. Badawy RAB, Curatolo JM, Newton M, Berkovic SF, Macdonell RAL. Changes in cortical excitability differentiate generalized and focal epilepsy. Ann Neurol. 2007;61:324-31.

9. Shorvon SD. The etiologic classification of epilepsy. Epilepsia. 2011:52:1052-7.

10. Crino PB. mTOR signaling in epilepsy: insights from malformations of cortical development. Cold Spring Harb Perspect Med 2015;5(4). doi:10.1101/cshperspect.a022442.

11. Allen AS, Berkovic SF, Cossette P, Delanty N, Dlugos D, Eichler EE et al. De novo mutations in epileptic encephalopathies. Nature. 2013;501:217-21.

12. Snowball A, Schorge S. Changing channels in pain and epilepsy: exploiting ion channel gene therapy for disorders of neuronal hyperexcitability. FEBS Lett. 2015:589:1620-34

13. Casillas-Espinosa PM, Powell KL, O'Brien TJ. Regulators of synaptic transmission: roles in the pathogenesis and treatment of epilepsy. Epilepsia. 2012;53:41-58.

14. Krab LC, Goorden SMI. Elgersma Y. Trends Genet: Oncogenes on my mind: ERK and MTOR signaling in cognitive diseases; 2008. p. 498-510.

15. Gorter JA, lyer A, White I, Colzi A, van Vliet EA, Sisodiya S, et al. Hippocampal subregion-specific microRNA expression during epileptogenesis in experimental temporal lobe epilepsy. Neurobiol Dis. 2014;62:508-20.

16. Kumar V, Zhang M-X, Swank MW, Kunz J, Wu G-Y. Regulation of dendritic morphogenesis by Ras-PI3K-Akt-mTOR and Ras-MAPK signaling pathways. J Neurosci. 2005:25:11288-99.

17. Lipton JO, Sahin M. The neurology of mTOR. Neuron. 2014;84:275-91.

18. Chotiner JK, Nielson J, Farris S, Lewandowski G, Huang F, Banos K, et al. Assessment of the role of MAP kinase in mediating activity-dependent transcriptional activation of the immediate early gene Arc/Arg3.1 in the dentate gyrus in vivo. Learn Mem. 2010;17:117-29.

19. Auerbach BD, Osterweil EK, Bear MF. Mutations causing syndromic autism define an axis of synaptic pathophysiology. Nature. 2011;480:63-8.

20. Osterweil EK, Krueger DD, Reinhold K, Bear MF. Hypersensitivity to $\mathrm{mGluR5}$ and ERK1/2 leads to excessive protein synthesis in the hippocampus of a mouse model of fragile $X$ syndrome. J Neurosci. 2010:30:15616-27.

21. Raab-Graham KF, Haddick PCG, Jan YN, Jan LY. Activity- and mTORdependent suppression of Kv1.1 channel mRNA translation in dendrites. Science. 2006;314:144-8.

22. Kelleher RJ, Govindarajan A, Jung H-Y, Kang H, Tonegawa S. Translational control by MAPK signaling in long-term synaptic plasticity and memory. Cell. 2004:116:467-79.
23. Köhrmann M, Luo M, Kaether C, DesGroseillers L, Dotti CG, Kiebler MA Microtubule-dependent recruitment of Staufen-green fluorescent protein into large RNA-containing granules and subsequent dendritic transport in living hippocampal neurons. Mol Biol Cell. 1999;10:2945-53.

24. Doyle M, Kiebler MA. Mechanisms of dendritic mRNA transport and its role in synaptic tagging. EMBO J. 2011;30:3540-52.

25. Jung H, Gkogkas CG, Sonenberg N, Holt CE. Remote control of gene function by local translation. Cell. 2014;157:26-40.

26. Kiebler MA, DesGroseillers L. Molecular insights into mRNA transport and local translation in the mammalian nervous system. Neuron. 2000;25:19-28.

27. Ramocki MB, Zoghbi HY. Failure of neuronal homeostasis results in common neuropsychiatric phenotypes. Nature. 2008;455:912-8.

28. DeBoer EM, Azevedo R, Vega TA, Brodkin J, Akamatsu W, Okano H, et al. Prenatal deletion of the RNA-binding protein HuD disrupts postnatal cortical circuit maturation and behavior. J Neurosci. 2014;34:3674-86.

29. Zhu X, Han X, Blendy JA, Porter BE. Decreased CREB levels suppress epilepsy. Neurobiol Dis. 2012;45:253-63.

30. Swanger SA, Bassell GJ. Dendritic protein synthesis in the normal and diseased brain. Neuroscience. 2013;232:106-27.

31. Laplante M, Sabatini DM. mTOR signaling in growth control and disease. Cell. 2012;149:274-93

32. Weston MC, Chen $\mathrm{H}$, Swann JW. Multiple roles for mammalian target of rapamycin signaling in both glutamatergic and GABAergic synaptic transmission. J Neurosci. 2012;32:11441-52.

33. Zeng $\mathrm{L}-\mathrm{H}$, Rensing NR, Wong $\mathrm{M}$. The mammalian target of rapamycin signaling pathway mediates epileptogenesis in a model of temporal lobe epilepsy. J Neurosci. 2009;29:6964-72.

34. Tang H, Long H, Zeng C, Li Y, Bi F, Wang J, et al. Rapamycin suppresses the recurrent excitatory circuits of dentate gyrus in a mouse model of temporal lobe epilepsy. Biochem Biophys Res Commun. 2012;420:199-204.

35. Tee AR, Fingar DC, Manning BD, Kwiatkowski DJ, Cantley LC, Blenis J. Tuberous sclerosis complex-1 and -2 gene products function together to inhibit mammalian target of rapamycin (mTOR)-mediated downstream signaling. Proc Natl Acad Sci USA. 2002;99:13571-6.

36. Bateup HS, Johnson CA, Denefrio CL, Saulnier JL, Kornacker K, Sabatini BL. Excitatory/inhibitory synaptic imbalance leads to hippocampal hyperexcitability in mouse models of tuberous sclerosis. Neuron. 2013:78:510-22.

37. Matsushita Y, Sakai Y, Shimmura M, Shigeto H, Nishio M, Akamine S, Sanefuji M, Ishizaki Y, Torisu H, Nakabeppu Y, Suzuki A, Takada H. Hyperactive mTOR signals in the proopiomelanocortin-expressing hippocampa neurons cause age- dependent epilepsy and premature death in mice. Sci Rep. 2016:6:1-12.

38. Nateri AS, Raivich G, Gebhardt C, Da Costa C, Naumann H, Vreugdenhil M, et al. ERK activation causes epilepsy by stimulating NMDA receptor activity. EMBO J. 2007;26:4891-901.

39. de Araújo HB, Vandresen-Filho S, Martins WC, Boeck CR, Tasca CI. NMDA preconditioning protects against quinolinic acid-induced seizures via PKA, PI3K and MAPK/ERK signaling pathways. Behav Brain Res. 2011:219:92-7.

40. Hu B, Liu C, Bramlett H, Sick TJ, Alonso OF, Chen S, et al. Changes in trkBERK1/2-CREB/Elk-1 pathways in hippocampal mossy fiber organization after traumatic brain injury. J Cereb Blood Flow Metab. 2004;24:934-43.

41. Gangarossa G, Sakkaki S, Lory P, Valjent E. Mouse hippocampal phosphorylation footprint induced by generalized seizures: focus on ERK, mTORC1 and Akt/GSK-3 pathways. Neuroscience. 2015:311:474-83.

42. Crespo-Biel N, Canudas AM, Camins A, Pallàs M. Kainate induces AKT, ERK and cdk5/GSK3 3 pathway deregulation, phosphorylates tau protein in mouse hippocampus. Neurochem Int. 2007;50:435-42.

43. Li Y, Peng Z, Xiao B, Houser CR. Activation of ERK by spontaneous seizures in neural progenitors of the dentate gyrus in a mouse model of epilepsy. Exp Neurol. 2010:224:133-45.

44. Ben J, de Oliveira PA, Gonçalves FM, Peres TV, Matheus FC, Hoeller AA, et al. Effects of pentylenetetrazole kindling on mitogen-activated protein kinases levels in neocortex and hippocampus of mice. Neurochem Res. 2014;39:2492-500.

45. Gangarossa G, Di Benedetto M, O'Sullivan GJ, Dunleavy M, Alcacer C, Bonito-Oliva A, et al. Convulsant doses of a dopamine D1 receptor agonist result in erk-dependent increases in Zif268 and Arc/Arg3.1 expression in mouse dentate gyrus. PLoS One. 2011;6:e19415.

46. Venigalla RKC, Turner M. RNA-binding proteins as a point of convergence of the PI3K and p38 MAPK pathways. Front Immunol. 2012;3:398. 
47. Bassell GJ. Warren ST. Neuron: Fragile X syndrome: loss of local mRNA regulation alters synaptic development and function; 2008. p. 201-14.

48. Darnell JC, Van Driesche SJ, Zhang C, Hung KYS, Mele A, Fraser CE, et al. FMRP stalls ribosomal translocation on mRNAs linked to synaptic function and autism. Cell. 2011;146:247-61.

49. Robison AJ. Emerging role of CaMKII in neuropsychiatric disease. Trends Neurosci. 2014;37:653-62.

50. Brown MR, Kronengold J, Gazula V-R, Chen Y, Strumbos JG, Sigworth FJ, et al. Fragile $X$ mental retardation protein controls gating of the sodium activated potassium channel Slack. Nat Neurosci. 2010;13:819-21.

51. Deng PY, Rotman Z, Blundon JA, Cho Y, Cui J, Cavalli V, et al. FMRP regulates neurotransmitter release and synaptic information transmission by modulating action potential duration via BK channels. Neuron. 2013;77:696-711.

52. Ferron $L$. Fragile $X$ mental retardation protein controls ion channel expression and activity. J. Physiol. 2016;594:5861-7.

53. Ferron L, Nieto-Rostro M, Cassidy JS, Dolphin AC. Fragile X mental retardation protein controls synaptic vesicle exocytosis by modulating $\mathrm{N}$-type calcium channel density. Nat Commun. 2014;5:3628.

54. Gross C, Yao X, Pong DL, Jeromin A, Bassell GJ. Fragile X mental retardation protein regulates protein expression and mRNA translation of the potassium channel Kv4.2. J Neurosci. 2011;31:5693-8.

55. Butler LS, Silva AJ, Abeliovich A, Watanabe Y, Tonegawa S, McNamara JO. Limbic epilepsy in transgenic mice carrying a $\mathrm{Ca}^{2+} /$ calmodulindependent kinase II alpha-subunit mutation. Proc Natl Acad Sci USA. 1995:92:6852-5.

56. Hagerman PJ, Stafstrom CE. Origins of epilepsy in fragile X syndrome. Epilepsy Curr. 2009;9:108-12.

57. Huang Y. Up-regulated cytoplasmic FMRP-interacting protein 1 in intractable temporal lobe epilepsy patients and a rat model. Int J Neurosci. 2015;126:542-51.

58. Oguro-Ando A, Rosensweig C, Herman E, Nishimura Y, Werling D, Bill BR, et al. Increased CYFIP1 dosage alters cellular and dendritic morphology and dysregulates mTOR. Mol Psychiatry. 2014;20:1069-78.

59. Sharma A, Hoeffer CA, Takayasu Y, Miyawaki T, McBride SM, Klann E, et al. Dysregulation of mTOR signaling in fragile $X$ syndrome. J Neurosci. 2010;30:694-702

60. Narayanan U, Nalavadi V, Nakamoto M, Thomas G, Ceman S, Bassell GJ, et al. S6K1 phosphorylates and regulates FMRP with the neuronal protein synthesis-dependent mTOR signaling cascade. J Biol Chem. 2008;283:18478-82

61. Bartley CM, O'Keefe RA, Bordey A. FMRP S499 is phosphorylated independent of mTORC1-S6K1 activity. PLoS One. 2014;9:e96956.

62. Curia G, Gualtieri F, Bartolomeo R, Vezzali R, Biagini G. Resilience to audiogenic seizures is associated with $\mathrm{p}$-ERK1/2 dephosphorylation in the subiculum of Fmr1 knockout mice. Front Cell Neurosci. 2013;7:46.

63. Muddashetty RS, Kelić S, Gross C, Xu M, Bassell GJ. Dysregulated metabotropic glutamate receptor-dependent translation of AMPA receptor and postsynaptic density-95 mRNAs at synapses in a mouse model of fragile X syndrome. J Neurosci. 2007;27:5338-48.

64. Witkin JM, Baez M, Yu J, Eiler WJA. mGlu5 receptor deletion does not confer seizure protection to mice. Life Sci. 2008;83:377-80.

65. Michalon A, Sidorov M, Ballard TM, Ozmen L, Spooren W, Wettstein JG, et al. Chronic pharmacological mGlu5 inhibition corrects fragile $X$ in adult mice. Neuron. 2012;74:49-56.

66. Santoro MR, Bray SM, Warren ST. Molecular mechanisms of fragile X syndrome: a twenty-year perspective. Annu Rev Pathol Mech Dis. 2012;7:219-45.

67. Hinman MN, Lou H. Diverse molecular functions of Hu proteins. Cell Mol Life Sci. 2008;65:3168-81.

68. Perrone-Bizzozero N, Bird CW. Role of HuD in nervous system function and pathology. Front. Biosci. 2013;5:554-63.

69. Sosanya N, Huang PPC, Cacheaux LP, Chen CJ, Nguyen K, PerroneBizzozero NI, et al. Degradation of high affinity HuD targets releases Kv1.1 mRNA from miR-129 repression by mTORC1. J Cell Biol. 2013;202:53-69.

70. Winden KD, Karsten SL, Bragin A, Kudo LC, Gehman L, Ruidera J, et al. A systems level, functional genomics analysis of chronic epilepsy. PLoS One. 2011;6:e20763.

71. Bolognani F, Contente-Cuomo T, Perrone-Bizzozero NI. Novel recognition motifs and biological functions of the RNA-binding protein HuD revealed by genome-wide identification of its targets. Nucleic Acids Res. 2009;38:117-30.
72. Tiruchinapalli DM, Caron MG, Keene JD. Activity-dependent expression of ELAV/Hu RBPs and neuronal mRNAs in seizure and cocaine brain. J Neurochem. 2008:107:1529-43.

73. Ince-Dunn G, Okano HJ, Jensen KB, Park WY, Zhong R, Ule J, et al. Neuronal Elav-like $(\mathrm{Hu})$ proteins regulate RNA splicing and abundance to control glutamate levels and neuronal excitability. Neuron. 2012;75:1067-79.

74. Qian F, Tang FR. Metabotropic glutamate receptors and interacting proteins in epileptogenesis. Curr Neuropharmacol. 2016;14:551-62.

75. Sosanya MN, Brager DH, Wolfe S, Niere F, Raab-Graham KF. Rapamycin reveals an mTOR-independent repression of Kv1.1 expression during epileptogenesis. Neurobiol Dis. 2015;73:96-105.

76. Tiruchinapalli DM, Ehlers MD, Keene JD. Activity-dependent expression of RNA binding protein HuD and its association with mRNAs in neurons. RNA Biol. 2008;5:157-68.

77. Sosanya NM, Cacheaux LP, Workman ER, Niere F, Perrone-Bizzozero NI, Raab-Graham KF. Mammalian Target of Rapamycin (mTOR) Tagging Promotes Dendritic Branch Variability through the Capture of $\mathrm{Ca}^{2+}$ / calmodulin-dependent protein kinase Ila (CaMKIla)mRNAs by the RNAbinding Protein HuD. J Biol Chem. 2015;jbc.M114.599399.

78. Liu X-B, Murray KD. Neuronal excitability and calcium/calmodulindependent protein kinase type II: location, location, location. Epilepsia. 2012;53(Suppl 1):45-52.

79. Cohen P, Frame S. The renaissance of GSK3. Nat Rev Mol Cell Biol. 2001;2:769-76.

80. Banko JL, Hou L, Poulin F, Sonenberg N, Klann E. Regulation of eukaryotic initiation factor $4 \mathrm{E}$ by converging signaling pathways during metabotropic glutamate receptor-dependent long-term depression. J Neurosci. 2006:26:2167-73

81. Hou L, Klann E. Activation of the phosphoinositide 3-kinase-Akt-mammalian target of rapamycin signaling pathway is required for metabotropic glutamate receptor-dependent long-term depression. J Neurosci. 2004:24:6352-61.

82. Farooq F, Balabanian S, Liu X, Holcik M, MacKenzie A. p38 Mitogen-activated protein kinase stabilizes SMN mRNA through RNA binding protein HuR. Hum Mol Genet. 2009;18:4035-45.

83. Lafarga V, Cuadrado A, Lopez de Silanes I, Bengoechea R, FernandezCapetillo O, Nebreda AR. p38 Mitogen-activated protein kinase- and HuR-dependent stabilization of p21(Cip1) mRNA mediates the G(1)/S checkpoint. Mol Cell Biol. 2009;29:4341-51.

84. Tiedje C, Ronkina N, Tehrani M, Dhamija S, Laass K, Holtmann H, et al. The p38/MK2-driven exchange between tristetraprolin and HuR regulates AU-rich element-dependent translation. PLoS Genet. 2012;8:e1002977.

85. Westmark CJ, Gourronc FA, Bartleson VB, Sayin U, Bhattacharya S, Sutula T, et al. HuR mRNA ligands expressed after seizure. J Neuropathol Exp Neurol. 2005:64:1037-45.

86. Brennan CM, Steitz JA. HuR and mRNA stability. Cell Mol Life Sci. 2001;58:266-77.

87. Ying Z, Najm I, Nemes A, Paula Pinheiro-Martins A, Alexopoulos A Gonzalez-Martinez J, et al. Growth-associated protein 43 and progressive epilepsy in cortical dysplasia. Ann Clin Transl Neurol. 2014;1:453-61.

88. Lonze BE, Ginty DD. Function and regulation of CREB family transcription factors in the nervous system. Neuron. 2002;35:605-23.

89. Barco A, Alarcon JM, Kandel ER. Expression of constitutively active CREB protein facilitates the late phase of long-term potentiation by enhancing synaptic capture. Cell. 2002;108:689-703.

90. Mirza N, Appleton R, Burn S, Carr D, Crooks D, du Plessis D, et al. Identifying the biological pathways underlying human focal epilepsy: from complexity to coherence to centrality. Hum Mol Genet. 2015:24:4306-16.

91. Dubey B, Porter B. CRTC1 nuclear localization in the hippocampus of the pilocarpine-induced status epilepticus model of temporal lobe epilepsy. Neuroscience. 2016;320:57-68.

92. Tao X, Finkbeiner S, Arnold DB, Shaywitz AJ, Greenberg ME. Ca ${ }^{2+}$ influx regulates $B D N F$ transcription by a CREB family transcription factordependent mechanism. Neuron. 1998;20:709-26.

93. Martínez-Levy GA, Rocha L, Lubin FD, Alonso-Vanegas MA, Nani A, Buentello-García RM, et al. Increased expression of BDNF transcript with exon VI in hippocampi of patients with pharmaco-resistant temporal lobe epilepsy. Neuroscience. 2016:314:12-21. 
94. Hong Z, Li W, Qu B, Zou X, Chen J, Sander JW, et al. Serum brain-derived neurotrophic factor levels in epilepsy. Eur J Neurol. 2014;21:57-64.

95. Xing J, Ginty DD, Greenberg ME. Coupling of the RAS-MAPK pathway to gene activation by RSK2, a growth factor-regulated CREB kinase. Science. 1996;273:959-63.

96. Beaumont TL, Yao B, Shah A, Kapatos G, Loeb JA. Layer-specific CREB target gene induction in human neocortical epilepsy. J Neurosci. 2012;32:14389-401.
97. French JA, Lawson JA, Yapici Z, Ikeda H, Polster T, Nabbout R, et al. Adjunctive everolimus therapy for treatment-resistant focal-onset seizures associated with tuberous sclerosis (EXIST-3): a phase 3, randomised, double-blind, placebo-controlled study. Lancet [Internet]. 2016. doi:10.1016/S0140-6736(16)31419-2

98. Sadowski K, Kotuslka K, Jóźwiak S. Management of side effects of mTOR inhibitors in tuberous sclerosis patients. Pharmacol Rep. 2016;68:536-42.

\section{Submit your next manuscript to BioMed Central} and we will help you at every step:

- We accept pre-submission inquiries

- Our selector tool helps you to find the most relevant journal

- We provide round the clock customer support

- Convenient online submission

- Thorough peer review

- Inclusion in PubMed and all major indexing services

- Maximum visibility for your research

Submit your manuscript at www.biomedcentral com/submit
() Biomed Central 